Research article

\title{
Interleukin-1beta and fibroblast growth factor receptor 1 cooperate to induce cyclooxygenase-2 during early mammary tumourigenesis
}

\author{
Johanna R Reed ${ }^{1}$, Ronald P Leon², Majken K Hall² and Kathryn L Schwertfeger ${ }^{1,2}$
}

\author{
${ }^{1}$ Microbiology, Immunology and Cancer Biology Graduate Program, University of Minnesota, 420 Delaware St. SE, Minneapolis, Minnesota 55455, \\ USA \\ ${ }^{2}$ Department of Laboratory Medicine and Pathology and Masonic Cancer Center, University of Minnesota, 420 Delaware St. SE, Minneapolis, \\ Minnesota 55455, USA
}

Corresponding author: Kathryn L Schwertfeger, schwe251@umn.edu

Received: 26 Nov 2008 Revisions requested: 26 Jan 2009 Revisions received: 17 Mar 2009 Accepted: 24 Apr 2009 Published: 24 Apr 2009

Breast Cancer Research 2009, 11:R21 (doi:10.1186/bcr2246)

This article is online at: http://breast-cancer-research.com/content/11/2/R21

(C) 2009 Reed et al.; licensee BioMed Central Ltd.

This is an open access article distributed under the terms of the Creative Commons Attribution License (http://creativecommons.org/licenses/by/2.0), which permits unrestricted use, distribution, and reproduction in any medium, provided the original work is properly cited.

\begin{abstract}
Introduction Inflammation within the tumour microenvironment correlates with increased invasiveness and poor prognosis in many types of cancer, including breast cancer. We have previously demonstrated that activation of a mouse mammary tumour virus (MMTV)-driven inducible fibroblast growth factor receptor 1 (iFGFR1) transgene in mammary epithelial cells results in an inflammatory response characterised by induction of inflammatory genes in the mammary gland. Specifically, we have observed increased levels of IL-1 $\beta$ expression in the mammary gland following activation of iFGFR1 and have used the iFGFR1 model to elucidate the function of $\mathrm{IL}-1 \beta$ in promoting iFGFR1-induced mammary lesions.
\end{abstract}

Methods To determine the functional consequences of IL-1 $\beta$ induction during FGFR1-induced mammary tumourigenesis, the effects of IL-1 $\beta$ inhibition on the formation of epithelial hyperplasias were examined using the MMTV-iFGFR1 transgenic mouse model. Further studies used a combination of the HC-11 mammary epithelial cell line that stably expresses
iFGFR1 and the MMTV-iFGFR1 transgenic mice to further define the mechanisms of IL-1 $\beta$ function.

Results Inhibition of IL-1 $\beta$ activity in vivo resulted in reduced iFGFR1-induced epithelial proliferation and formation of hyperplastic structures. Further studies demonstrated that treatment of mammary epithelial cells with IL-1 $\beta$-induced expression of cyclooxygenase (Cox)-2 both in vitro and in vivo. Finally, inhibition of Cox-2 prior to activation of iFGFR1 in the transgenic mice also resulted in decreased iFGFR1-induced formation of hyperplastic structures.

Conclusions The results from these studies indicate that targeting the inflammatory cytokine IL-1 $\beta$ partially inhibits iFGFR1-induced formation of early-stage mammary lesions, in part through induction of Cox-2. These findings demonstrate that activation of a growth factor receptor in mammary epithelial cells results in increased expression of inflammatory mediators, which cooperate to promote the initiation of hyperplastic lesions in the mammary gland.

\section{Introduction}

Inflammation is a well-known risk factor for tumour development and correlates with increased invasiveness and poor prognosis in a variety of cancers [1]. It is well-established that chronic inflammation that is driven by extrinsic factors promotes several types of cancer, including gastric, hepatic and gastrointestinal cancers [1]. However, inflammation has also been correlated with the development of cancers that are not typically associated with chronic inflammatory states, such as breast cancer. There has been ongoing interest in the concept that intrinsic factors, such as activation of an oncogene within epithelial cells, induce a state of localised inflammation that subsequently promotes tumourigenesis [2].

Recent epidemiological studies support a role for anti-inflammatory drugs in the reduction of breast cancer risk [3-7].

Cox-2: cyclooxygenase 2; ELISA: enzyme linked immunosorbent assay; FGFR1: fibroblast growth factor receptor 1; GAPDH: glyceraldehyde 3-phosphate dehydrogenase; H\&E: haematoxylin and eosin; iFGFR1: inducible fibroblast growth factor receptor 1; Ig: immunoglobulin; IL: interleukin; IL-1R: interleukin-1 receptor; i.p.: intraperitoneally; MMTV: mouse mammary tumour virus; NF: nuclear factor; NSAID: non-steroidal anti-inflammatory drug; pH3: phospho-histone H3; rm: recombinant murine; RT-PCR: reverse transcription polymerase chain reaction. 
Furthermore, inflammatory cytokines, such as IL- $1 \beta$, and other mediators of inflammation have been linked to breast cancer formation and recurrence $[8,9]$. Cyclooxygenase (Cox)-2 is a primary downstream target of inflammatory cytokines and has been linked to proliferation, suppression of apoptosis, induction of genomic instability, resistance to treatment and angiogenesis in breast cancer $[10,11]$. Although Cox-2 is commonly associated with inflammatory cells, studies have also demonstrated that Cox-2 is induced by activation of oncogenes within breast cancer cells $[12,13]$. Therefore, Cox- 2 is likely to represent an important component of intrinsically induced inflammation in breast cancer. Understanding the mechanisms by which intrinsic factors, such as oncogenes, induce inflammation is critical for successfully developing and using antiinflammatory strategies to target breast cancer formation and recurrence.

Using an inducible mouse model of mammary tumourigenesis, we previously demonstrated that activation of an inducible fibroblast growth factor receptor-1 (iFGFR1) transgene within epithelial cells resulted in the formation of hyperplastic budding structures within 48 hours of iFGFR1 activation $[14,15]$. These early structures were characterised by increased proliferation and lack of formation of a proper lumen surrounded by the epithelium [15]. Longer-term activation demonstrated that iFGFR1 activation promoted a loss of myoepithelial cells, and increased angiogenesis, formation of locally invasive lesions and, ultimately, mammary tumour formation [14,15]. Further studies of this model demonstrated that iFGFR1 activation in the mammary gland induced a rapid, localised inflammatory response, characterised by recruitment of macrophages to the epithelial structures and induction of inflammatory genes by microarray analysis [14]. Activation of iFGFR1 has been shown to promote proliferation, survival, migration, invasion and epithelial-mesenchymal transition of mammary epithelial cells [16]. Furthermore, FGFR1 is amplified in 10\% of human breast tumours and has been linked to a poor response to treatment in breast cancer patients [17]. However, the mechanisms by which FGFR1 activation in epithelial cells induces pro-tumourigenic effects in the microenvironment are only beginning to be understood.

Our current studies focus on the ability of iFGFR1 activation to promote an intrinsic pathway of inflammation using a transgenic mouse model. We have found that activation of iFGFR1 within mammary epithelial cells results in the expression of proinflammatory genes, such as $\mathrm{IL}-1 \beta$ and Cox-2, and that these mediators are important for iFGFR 1 -induced early-stage tumourigenesis. These studies demonstrate that activation of an oncogenic growth factor signalling pathway within mammary epithelial cells induces a localised inflammatory response that promotes the formation of early-stage mammary lesions.

\section{Materials and methods \\ Animals}

Generation of mouse mammary tumour virus (MMTV)-iFGFR1 transgenic mice has been described previously [15] and the mice were obtained from Dr Jeff Rosen (Baylor College of Medicine, Houston, TX, USA). Animal care and procedures were approved by the Institutional Animal Care and Use Committee of the University of Minnesota and were in accordance with the procedures detailed in the Guide for Care and Use of Laboratory Animals.

\section{Treatment of mice}

For iFGFR1 activation, six-week-old female mice were injected intraperitoneally (i.p.) with $1 \mathrm{mg} / \mathrm{kg}$ AP20187 (Ariad Pharmaceuticals, Cambridge, MA, USA) twice weekly. Mice were sacrificed at 48 hours and four weeks post-injection and mammary glands from at least three mice were analysed per time point. For the IL-1 $\beta$ neutralisation studies, the mice were treated as described previously [18]. Briefly, mice were injected i.p. with $4 \mu \mathrm{g} / \mathrm{g} \mathrm{IL}-1 \beta$ antibody (AB-401-NA, R\&D Systems, Minneapolis, MN, USA) 24 hours prior to AP20187 treatment and in conjunction with AP20187 for an additional 48 hours. Control mice were injected with isotype control total immunoglobulin (Ig) G (R\&D Systems, Minneapolis, MN, USA) for the same time frame. For inhibition of Cox-2 by celecoxib, four-week-old female MMTV-iFGFR1 transgenic mice and non-transgenic littermate control mice were fed standard mouse chow (Harlan Laboratories, Madison, WI, USA) enriched with celecoxib (obtained as $200 \mathrm{mg}$ capsules) at a concentration of $1000 \mathrm{mg} / \mathrm{kg}$ (Harlan Laboratories, Madison, WI, USA). Celecoxib-treated mice and control mice, given standard mouse chow only, were fed for one week. All mice were then injected i.p. with $1 \mathrm{mg} / \mathrm{kg}$ AP20187. Mice were maintained on the celecoxib or control diets and were sacrificed 48 hours post-injection. Mammary glands from five mice per treatment group were removed for whole mount and histological analysis.

\section{Mammary gland whole mounts, histology and measurement of epithelial budding}

Whole mounts were prepared as described previously [14]. For embedding, sectioning and immunohistochemistry, mammary glands were fixed for two hours in 4\% paraformaldehyde and embedded in paraffin. For histological analysis, the glands were sectioned and stained with H\&E using standard histological protocols. To quantify epithelial budding structures, six images were taken per mammary gland section at $10 \times$ magnification. Five sections were analysed per gland, each approximately $100 \mu \mathrm{m}$ apart, to compensate for variability within the gland. In addition, only epithelial structures distal to the lymph node were included in the analyses due to the predominant localisation of the hyperplastic phenotype along ducts leading to terminal end buds. The total number of epithelial structures was counted and expressed as a percentage of structures that contain epithelial buds. At least three mice and 200 epithelial 
structures were analysed for each genotype and treatment. All statistical analyses were performed using the unpaired student's t-test to compare two means (GraphPad Prism, La Jolla, CA, USA).

\section{Immunohistochemistry}

The following antibodies and dilutions were used for immunohistochemistry: rabbit polyclonal IL-1 $\beta$ (sc-7884), 1:100, goat polyclonal Cox-2 (sc-1747), 1:100, (Santa Cruz Biotechnology, Santa Cruz, CA, USA), mouse monoclonal phospho-histone $\mathrm{H} 3$ (pH3; 05-806, Millipore, Billerica, MA, USA). Immunostaining was performed either with (IL-1 $\beta, \mathrm{pH} 3)$ or without (Cox-2) sodium citrate antigen retrieval, as described previously [19]. pH3 and Cox-2 positive cells were counted and calculated relative to the number of total epithelial cells. At least $\mathbf{2 0 0 0}$ cells from a total of three mice per treatment group were counted for each dataset. All statistical analyses were performed using the unpaired student's t-test to compare two means.

\section{RNA isolation and quantitative RT-PCR analysis}

Transgenic and non-transgenic six-week mice were treated for 8, 16, 24 and 48 hours with AP20187, IgG isotype control and/or IL-1 $\beta$ blocking antibody as indicated. Mammary glands were isolated, the lymph nodes were removed and the mammary glands were ground under liquid nitrogen and lysed in 2 mls of Trizol (Invitrogen, Carlsbad, CA, USA). RNA was extracted from monolayer cells using Trizol as recommended by the manufacturer. cDNA was generated using the Quantitect Reverse Transcription kit (Qiagen, Valencia, CA, USA). One-tenth of the final reaction volume was used in quantitative SYBR (Synergy Brands) green RT-PCR reactions as described previously [20] using the Bio-Rad iQ5 system (BioRad, Hercules, CA, USA). Relative quantification of the expression of each gene was calculated and normalised to averaged cyclophilin and glyceraldehyde 3-phosphate dehydrogenase (GAPDH) expression levels as indicated using the $2^{-\Delta \Delta C t}$ method [21]. The following primer sequences were used: IL-1 $\beta$ 5'-GCAACTGTTCCTGAACTCAAC-3' and 5'ATCTTTTGGGGTCCGTCAACT-3', Cox-2 5' TGAGCAACTATTCCAAACCAG-3' and GCACGTAGTCTTCGATCACTATC, cyclophilin 5'-TGAGCACTGGGGAGAAAGG-3' and 5'TTGCCATCCAGCCACTCAG-3', GAPDH 5'-TGACCACAGTCCATGCCATC-3' and 5'-GACGGACACATTGGGGGTAG-3'. All statistical analyses were performed using the unpaired student's t-test to compare two means.

\section{Cell culture and immunoblot analysis}

Generation of HC-11 cells stably expressing the iFGFR1 construct was described previously [16] and the cells were obtained from Dr Jeff Rosen (Baylor College of Medicine, Houston, TX, USA). The cells were incubated in serum-free RPMI media for 16 hours prior to treatment with either the indicated amounts of recombinant IL-1 $\beta$ (Pierce Endogen, Rockford, IL, USA) or with $30 \mathrm{nM}$ AP20187 for the indicated times. The cells were lysed in radio immuno precipitation assay buffer and protein-containing supernatants were generated by centrifugation. Equal amounts of protein were analyaed by SDSPAGE and immunoblotting analysis was performed with the following antibodies at a dilution of 1:1000: phospho-p65 (3033), p65 (4764), Cox-2 (4842) and $\beta$-tubulin (2146) (Cell Signaling Technology, Beverly, MA, USA). Densitometry was performed using an Alphalmager 3400 (Alpha Innotech, San Leandro, CA, USA).

\section{Co-culture and ELISA analysis}

RAW 264.7 cells (American Type Culture Collection, Manassas, VA, USA) and HC-11/R1 cells were plated at equal densities in six-well tissue culture plates and allowed to grow for 48 hours in complete HC-11/R1 media. The cells were incubated overnight in serum-free RPMI media and treated with either 30 nM AP20187 or an equal amount of ethanol as a solvent control. Following eight hours of treatment, the cells were harvested in Trizol and IL-1 $\beta$ expression levels were analysed as described above. Following 24 hours, conditioned medium was harvested and was analysed using an ELISA to quantify the amount of IL-1 $\beta$ in the media following the manufacturer's protocols (R\&D Systems, Minneapolis, MN, USA). All statistical analyses were performed using the unpaired students ttest to compare two means.

\section{Migration assays}

Migration assays were performed as described previously [16]. Briefly, HC-11/R1 cells were grown to confluence and incubated overnight in serum-free medium. A p20 pipet tip was used to make a scratch down the centre of the well and pictures were taken of the scratch prior to treatment of cells with $30 \mathrm{nM}$ AP20187 and/or $5 \mathrm{ng} / \mathrm{ml}$ recombinant IL-1 $\beta$. After 18 hours, pictures were taken again and the area of the gap closure was quantified using Leica LAS software (Leica Microsystems, Wetzlar, Germany). All statistical analyses were performed using the unpaired student's t-test to compare two means.

\section{Results \\ Activation of iFGFR1 in mammary epithelial cells induces expression of the inflammatory cytokine IL-1 $\beta$ in the mammary gland}

FGFR1 is amplified in approximately 8 to $10 \%$ of human breast cancers [22]. However, due to lack of a ligand that specifically activates FGFR1 without activating the other FGFRs, a model was developed to study the effects of FGFR1 activation specifically in mammary epithelial cells [15]. In this model, a modified, membrane-targeted FGFR1 (iFGFR1) that lacks an extracellular domain is activated by treatment of cells with a lipid-soluble dimeriser, AP20187. Upon binding, AP20187 induces homodimerisation and activation of the receptor. The effects of activating this FGFR1 construct in mammary epithelial cells in cell culture and in vivo using the MMTV-iFGFR1 transgenic mouse model have been described previously [14- 
16,23]. Specifically, iFGFR1 activation in the mammary gland results in the rapid formation of hyperplastic epithelial structures within 48 hours accompanied by an inflammatory response, characterised by rapid macrophage recruitment and increased expression of several inflammatory genes $[14,15]$.

To identify inflammatory genes that contribute to the iFGFR1induced inflammatory response, we used quantitative RT-PCR analysis to examine the expression of several candidate genes in the mammary gland following treatment of mice with AP20187, which activates iFGFR1. Interestingly, we found a significant induction of IL-1 $\beta$, which is a critical cytokine in the inflammatory response that has also been linked to breast cancer invasiveness and recurrence $[8,9]$. As shown in Figure 1a, expression of IL-1 $\beta$ mRNA increased significantly in the mammary gland within eight hours and remained elevated following 24 hours of iFGFR1 activation. Treatment of non-transgenic littermates with AP20187 did not induce a similar increase in IL$1 \beta$ expression, demonstrating that this response was not a general inflammatory reaction to either the AP20187 dimeriser or the solvent used for the injections (Figure 1a). In addition to gene expression levels, immunohistochemical analysis of mammary gland sections demonstrated an increase in IL-1 $\beta$ protein expression following 48 hours of iFGFR 1 activation in comparison to non-transgenic littermates treated with AP20187 (Figures 1b,c). Analysis of a four-week time-point revealed sustained expression of IL-1 $\beta$ associated with iFGFR1-induced hyperplastic lesions (Figures 1d,e). These results demonstrate that activation of iFGFR1 in mammary epithelial cells results in expression of the key inflammatory mediator, $\mathrm{IL}-1 \beta$, in the mammary gland.

Because IL- $1 \beta$ is secreted, the cellular source of the IL- $1 \beta$ in the mammary gland is difficult to discern using immunohistochemistry. Therefore, we utilised in vitro assays to determine whether iFGFR1 directly induces expression of IL-1 $\beta$ in mammary epithelial cells. For these studies, we used a derivative of the $\mathrm{HC}-11$ cell line, which is a mouse mammary epithelial cell line derived from a mid-pregnant Balb/c mammary gland [24]. To study the consequences of iFGFR1 activation in these cells, clones of HC-11 cells were previously generated that stably express iFGFR1 (HC-11/R1) [16]. Published studies have demonstrated that activation of iFGFR1 in these cells promotes proliferation, survival, migration and invasion $[16,23]$. Therefore, these cells represent a relevant in vitro model with which to examine iFGFR1-mediated mechanisms of mammary tumourigenesis.

To determine the effects of iFGFR 1 activation on IL- $1 \beta$ expression, the cells were treated with $30 \mathrm{nM}$ AP20187 and IL-1 $\beta$ expression was analysed using both quantitative RT-PCR and ELISA assays. Although we detected a small increase in IL-1 $\beta$ mRNA expression (Figure 1f), this induction was not statistically significant. Furthermore, no IL-1 $\beta$ protein was detected in conditioned media using an ELISA assay (data not shown).
Therefore, we hypothesised that activation of iFGFR1-induced expression of IL-1 $\beta$ requires the presence of other cell types. We had previously observed a rapid accumulation of macrophages around the hyperplastic epithelial structures following iFGFR1 activation in the mammary gland [14]. Furthermore, macrophages are known to secrete high levels of IL-1 $\beta$ in response to inflammatory stimuli [25]. Therefore, we analysed IL-1 $\beta$ expression levels following activation of iFGFR 1 in epithelial cell/macrophage co-cultures. Interestingly, significant increases in both IL-1 $\beta$ mRNA and protein were detected in the co-cultures (Figures 1f,g). Similar results were found when the HC-11/R1 cells were co-cultured with mouse bone marrow-derived macrophages (data not shown). These results suggest that interactions between epithelial cells and macrophages may be required to induce IL-1 $\beta$ following iFGFR1 activation in the mammary epithelial cells in vitro.

\section{IL-1 $\beta$ promotes the formation of iFGFR1-induced hyperplasias in vivo}

Based on the increased expression of IL-1 $\beta$ following FGFR1 activation and the link between IL-1 $\beta$ and breast cancer [8], we hypothesised that IL-1 $\beta$ may be an important factor in the formation of iFGFR1-induced proliferative lesions. To examine this hypothesis, we used a systemic IL- $1 \beta$ neutralisation strategy similar to that described previously [18]. For these experiments, either an IL-1 $\beta$ neutralising antibody or an equivalent amount of an isotype control goat lgG antibody was administered i.p. to six-week-old female transgenic mice 24 hours prior to iFGFR1 activation. The mice were then treated with AP20187 to activate iFGFR1 in conjunction with daily treatments of either IL-1 $\beta$ blocking antibody or an isotype control goat $\lg G$ for 48 hours. Following the treatments, the mammary glands were analysed by whole mount analysis and sections were analysed for the percentage of budding epithelial structures, proliferation and macrophage recruitment. Analysis of whole mounts revealed that IL-1 $\beta$ inhibition led to an overall decrease in hyperplastic budding, particularly associated with the terminal-end buds and the subtending ducts (see Additional data file 1). Further studies were performed to validate these alterations in histological sections. We found that although inhibition of IL-1 $\beta$ did not completely abolish hyperplastic budding of the epithelium, there was a significant decrease in the total number of budding structures present within mammary glands from mice that had been treated with the IL-1 $\beta$ blocking antibody (Figures $2 a$ to $2 d$ ). Furthermore, there was a corresponding decrease in the percentage of proliferating epithelial cells as measured by quantification of $\mathrm{pH} 3$ immunofluorescence (Figure 2e). Interestingly, analysis of macrophage recruitment revealed that inhibition of IL-1 $\beta$ activity did not affect iFGFR1-induced recruitment of macrophages to the epithelium (data not shown). Together, these studies suggest that although IL-1 $\beta$ may not be critical for the recruitment of macrophages observed in this model, IL-1 $\beta$ activity contributes to epithelial proliferation during the formation of the iFGFR1-induced lateral budding phenotype. 
(a)
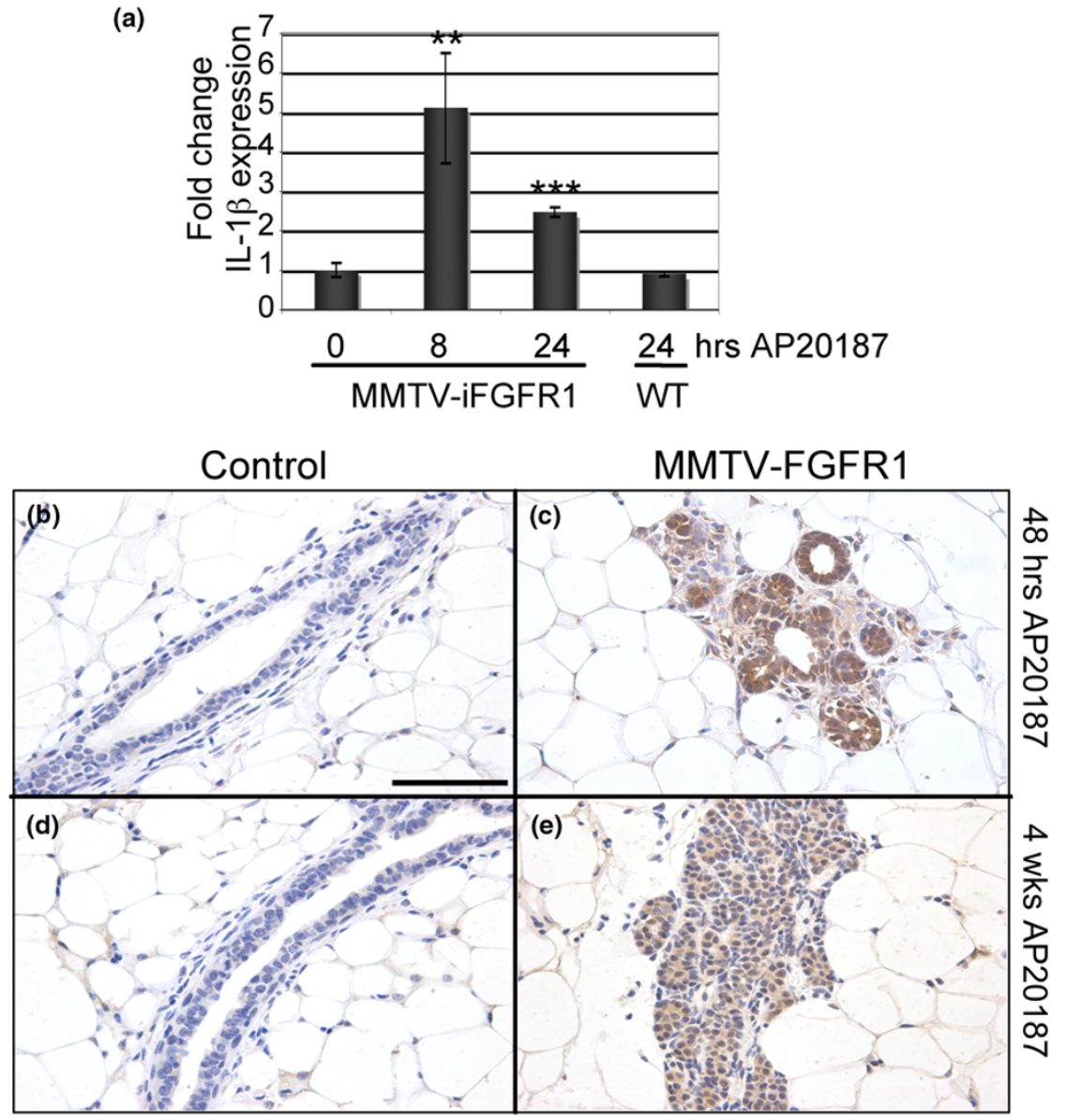

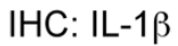

(f)

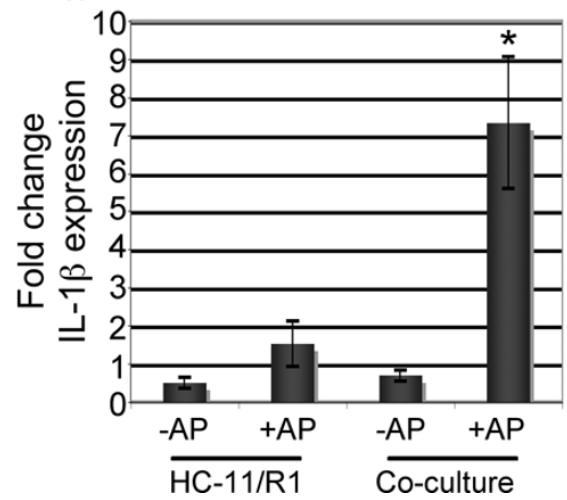

(g)

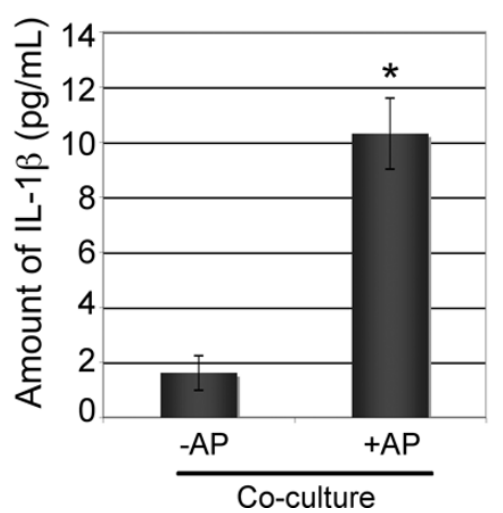

iFGFR1 activation induces IL-1 $\beta$ expression in the mammary gland. (a) Mouse mammary tumour virus (MMTV) inducible fibroblast growth factor receptor 1 (iFGFR1) transgenic mice and non-transgenic littermate controls were treated with AP20187 for 8 and/or 24 hours. Non-treated mice were used as the baseline control. Quantitative RT-PCR was performed on RNA extracted from whole mammary gland tissue and normalised to expression levels of cyclophilin. Mammary glands from three separate mice were analysed per time point. Error bars represent standard error of the mean. ${ }^{\star \star} P<0.01,{ }^{\star \star \star} P<0.001$. (b to e) Immunohistochemical analysis of mammary gland tissue sections from MMTV-iFGFR1 transgenic mice and non-transgenic littermate controls following either 48 hours or 4 weeks of AP20187 treatment. Images are representative of results from the analysis of three mice per genotype and treatment time. (f) Quantitative RT-PCR analysis of IL-1 $\beta$ expression levels (normalised to glyceraldehyde 3phosphate dehydrogenase). Either HC-11/R1 cells or HC-11/R1-RAW264.7 co-cultures were treated with AP20187 (+AP) or solvent (-AP) for four hours and analysed for IL-1 $\beta$ gene expression. * $P<0.05$. (g) HC-11/R1-RAW264.7 co-cultures were treated with AP20187 (+AP) or solvent (-AP) for 18 hours and conditioned media was analysed using an ELISA. * $P<0.05$. 
Figure 2

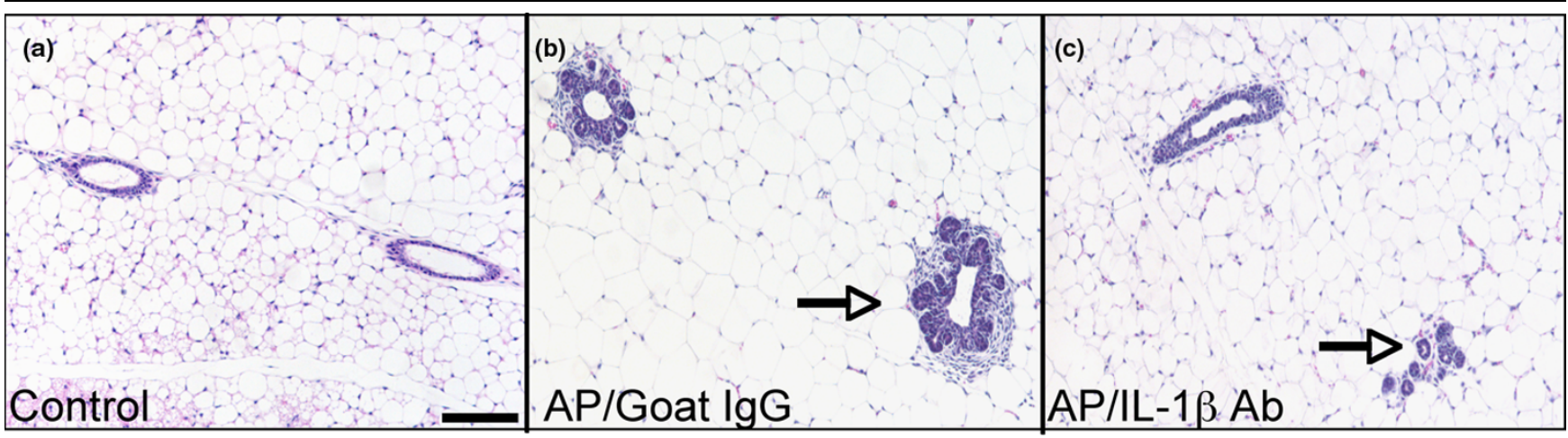

(d)

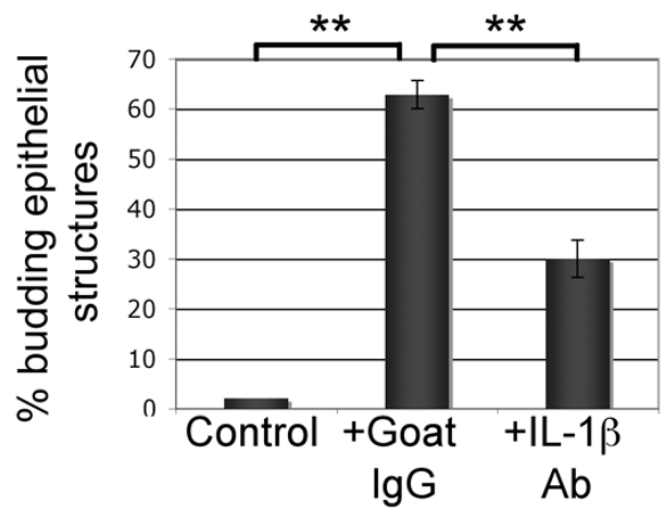

(e)

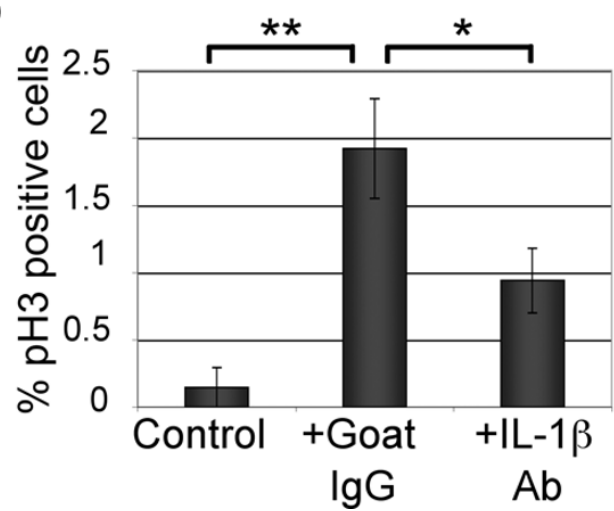

Analysis of mammary glands from iFGFR1 transgenic mice following activation of iFGFR1 and treatment with an IL-1 $\beta$ neutralising antibody. H\&Estained sections from (a) non-treated control mice, (b) transgenic mice treated with AP20187 and goat lgG, and (c) transgenic mice treated with AP20187 and IL-1 $\beta$ blocking antibody (Ab). Arrows indicate epithelial budding structures. Scale bar $=100 \mu \mathrm{M}$. (d) Budding structures were quantified by counting epithelial structures in H\&E-stained sections (three mice per treatment group). Decreased epithelial budding was observed following treatment with AP20187 and the IL-1 $\beta$ antibody compared with treatment with AP20187 and lgG. ${ }^{\star \star} P<0.01$ (e) Sections were immunostained with an antibody to phospho-histone $\mathrm{H} 3(\mathrm{pH} 3)$, a marker of mitosis, and the percentage of $\mathrm{pH} 3$ positive epithelial cells was determined. Decreased numbers of $\mathrm{pH} 3$ were observed following treatment with AP20187 and the IL-1 $\beta$ antibody compared with treatment with AP20187 and IgG. * $P<$ $0.05,{ }^{\star *} P<0.01$. iFGFR1 $=$ inducible fibroblast growth factor receptor 1 .

\section{IL-1 $\beta$ induces activation of NFKB in HC-11/R1 mammary epithelial cells}

Based on the results from the in vivo studies, we hypothesised that IL-1 $\beta$ acts on the mammary epithelial cells to contribute to the formation of iFGFR1-induced hyperplastic lesions. Therefore, initial studies were performed to ascertain the ability of mammary epithelial cells to respond to IL-1 $\beta$ stimulation by examining activation of downstream signalling pathways using the HC-11/R1 cell line described previously. Initial studies using both quantitative RT-PCR and immunoblot analysis demonstrated that the HC-11/R1 cells express the IL-1 receptor (IL-1R) (data not shown). Further studies were performed using both dose-response and time-course analyses to examine the activation of nuclear factor (NF) $\kappa B$, which is a key downstream target of IL-1 $\beta$ in other cell types [26]. Treatment of $\mathrm{HC}-11 / \mathrm{R} 1$ cells with recombinant murine (rm) $\mathrm{IL}-1 \beta$ resulted in a rapid induction of phosphorylation of the p65 subunit of NFKB within 15 minutes of treatment as shown by immunoblot analysis (Figures 3a,b). Based on the observation that $5 \mathrm{ng} / \mathrm{ml}$ of rmlL- $1 \beta$ was within the linear range of response
(Figure 3a), this concentration was used for the remainder of the studies. These results demonstrate that the HC-11/R1 mammary epithelial cell line responds to $\mathrm{rmL}-1 \beta$ treatment by activating a well-defined downstream signalling pathway.

\section{IL-1 $\beta$ and iFGFR1 cooperate to promote migration of HC- 11/R1 cells}

Previous studies have demonstrated that treatment of breast cancer cells in culture with IL-1 $\beta$ promotes cell proliferation and migration $[27,28]$. Therefore, we examined the ability of IL$1 \beta$ to promote these properties in non-transformed mammary epithelial cells using 3-[4,5-dimethylthiazol-2-yl]-2,5-diphenyl tetrazolium bromide and scratch wounding assays, respectively. In contrast to studies of breast cancer cells, treatment of HC-11/R1 cells with rmIL-1 $\beta$ alone did not promote either proliferation (data not shown) or migration (Figures $3 c, d$ ). Because IL-1 $\beta$ can promote these properties in breast cancer cells, we hypothesised that IL-1 $\beta$ may act cooperatively with another oncogenic stimulus to promote tumourigenic changes. Therefore, we stimulated HC-11/R1 cells with 
(a)

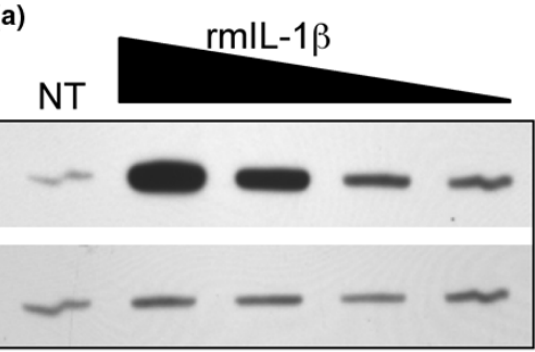

(b)

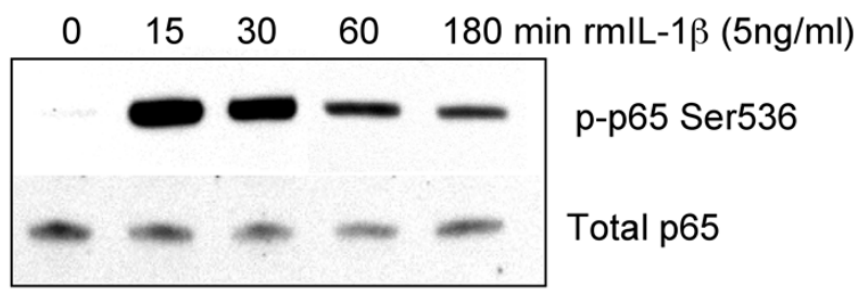

(c)

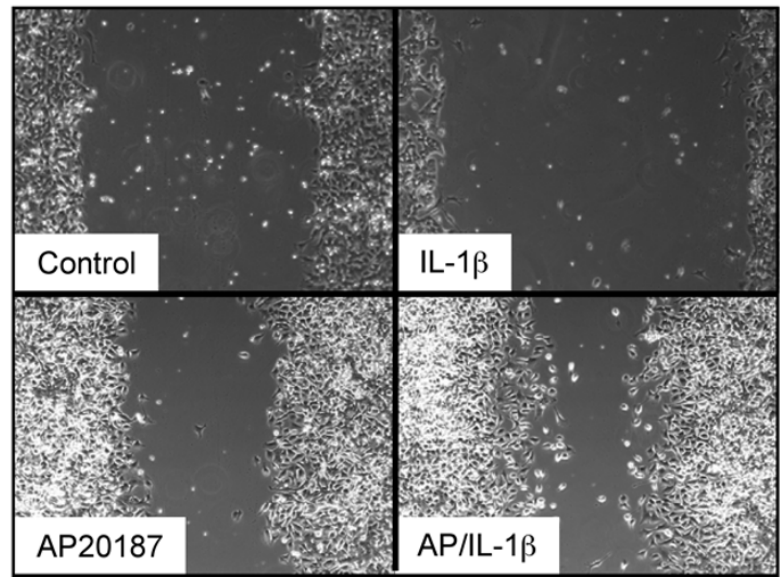

(d)

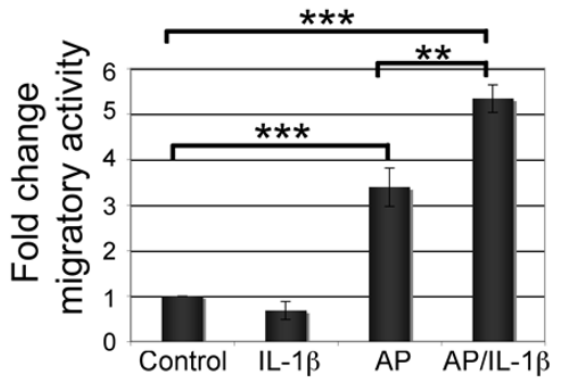

IL-1 $\beta$ induces NFKB activation and cooperates with iFGFR 1 to promote migration in HC-11/R1 cells. (a) HC-11/R1 cells were incubated in serumfree medium overnight and then stimulated with the following concentration of recombinant IL-1 $\beta$ for 15 minutes: $50,5,0.5$ and $0.05 \mathrm{ng} / \mathrm{ml} \mathrm{IL-1 \beta}$. Immunoblot analysis was performed to detect levels of phospho-p65 (upper panel) and total p65 (lower panel) as a loading control. (b) HC-11/R1 cells were treated with $5 \mathrm{ng} / \mathrm{ml}$ recombinant murine $(\mathrm{rm}) \mathrm{IL}-1 \beta$ for the indicated times and immunoblot analysis was performed as described in a. (c, d) At confluency, HC-11/R1 cells were serum starved for 24 hours, scratched using a pipet tip and allowed to recover for 18 hours in the presence of IL-1 $\beta$, AP20187 or both. Pictures were taken immediately after the scratch and 18 hours later and were used to determine the extent of migration (d) measuring the changes in area between the scratch surfaces. Error bars represent standard error of the mean. ${ }^{\star \star} P<0.01,{ }^{\star \star \star} P<0.001$. iFGFR1 = inducible fibroblast growth factor receptor 1 ; $\mathrm{NF}=$ nuclear factor.

AP20187, which activates iFGFR1, and rmlL-1 $\beta$ either alone or in combination. Addition of IL-1 $\beta$ to the media did not significantly affect iFGFR1-induced proliferation of the HC-11/R1 cells (data not shown). However, addition of both AP20187 and $\mathrm{rmlL}-1 \beta$ to the media promoted a significant increase in migration in comparison with iFGFR1 activation alone (Figures $3 c, d)$. These studies suggest that although treatment of nontransformed mammary epithelial cells with IL-1 $\beta$ alone does not promote the acquisition of tumourigenic properties, IL-1 $\beta$ may act cooperatively with other oncogenic stimuli to promote these properties during tumour formation.

\section{IL-1 $\beta$ and iFGFR1 induce expression of Cox-2, which promotes migration of HC-11/R1 cells in vitro}

To identify downstream targets of IL-1 $\beta$ in mammary epithelial cells, we asked whether IL-1 $\beta$ could induce expression of Cox2 , a known IL-1 $\beta$ target [26], in the HC-11/R1 cells. For these studies, HC-11/R1 cells were treated with rmIL-1 $\beta$ and Cox-2 expression was evaluated by quantitative RT-PCR and immu- noblot analysis. Quantitative RT-PCR analysis demonstrated a modest induction of both Cox-2 mRNA and protein following four and six hours of IL-1 $\beta$ treatment, respectively (Figures $4 a, c)$. Because Cox-2 is a known downstream target of growth factor signalling pathways [12,13], we explored the possibility that activation of iFGFR1 also induces Cox-2 expression. HC11/R1 cells were treated with AP20187 to activate iFGFR1 and Cox-2 expression was analysed by both quantitative RTPCR and immunoblot analysis. As shown in Figure 4b, Cox-2 mRNA and protein expression were rapidly induced in the $\mathrm{HC}$ 11/R1 cells following iFGFR activation. Because Cox-2 is induced by both iFGFR1 and IL-1 $\beta$ in the HC-11/R1 mammary epithelial cells, we predicted that activation of both growth factor and cytokine-induced signalling pathways would result in a cooperative induction of Cox-2 expression. In agreement with this prediction, quantitative RT-PCR analysis revealed an additive increase in Cox-2 expression following activation of both iFGFR1 and IL-1 $\beta$ signalling pathways in comparison with either stimulation alone (Figure $4 d$ ). These results suggest that 
Figure 4
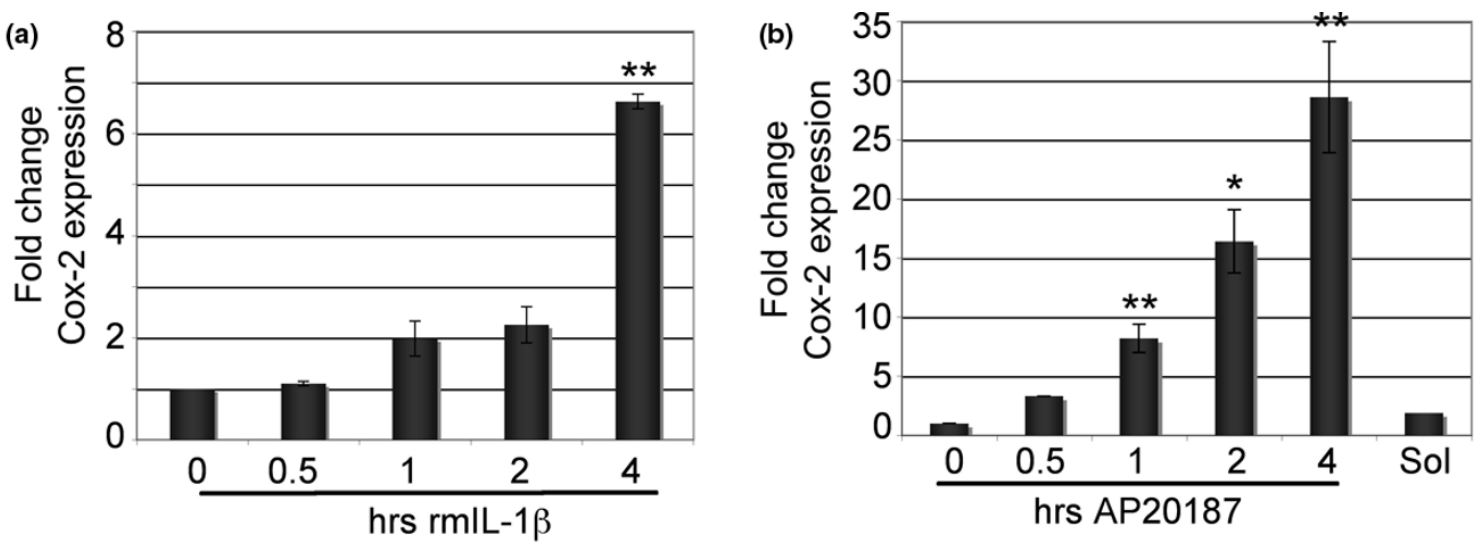

(c)

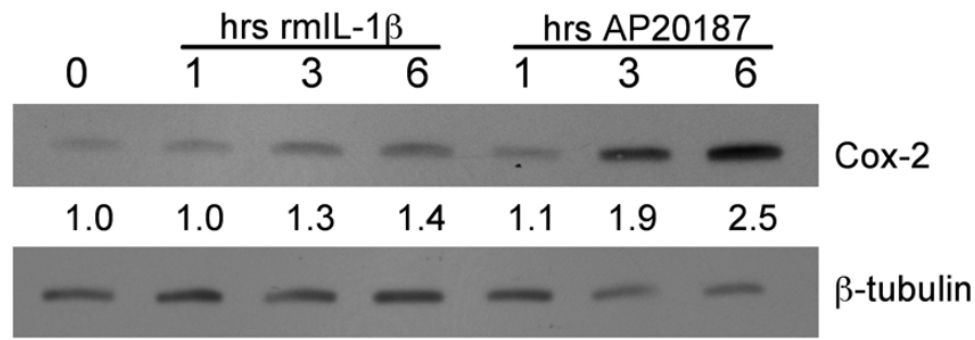

(d)

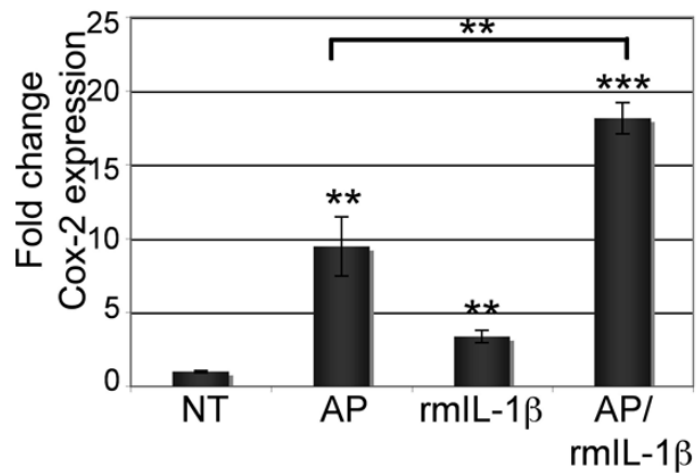

(e)

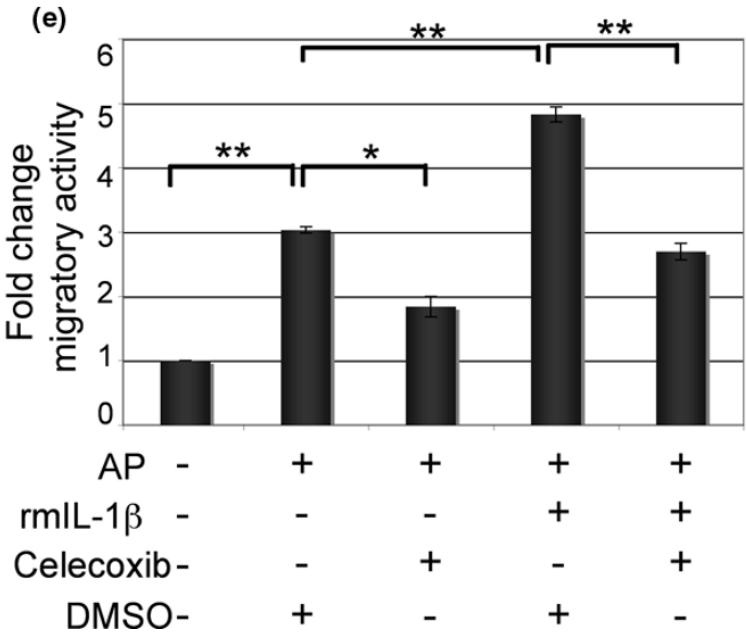

$\mathrm{IL}-1 \beta$ and iFGFR 1 induce expression of Cox-2 in HC-11/R1 cells. (a) HC-11/R1 cells were treated with $5 \mathrm{ng} / \mathrm{ml} \mathrm{rmlL}-1 \beta$ for the indicated times. Quantitative RT-PCR was used to analyse IL-1 $\beta$ mRNA expression (normalised to levels of cyclophilin and glyceraldehyde 3-phosphate dehydrogenase (GAPDH)). Error bars represent standard error of the mean. ${ }^{* *} P<0.01$. (b) HC-11/R1 cells were treated with either $30 \mathrm{nM}$ AP20187 or ethanol (Sol) for the indicated times and cyclooxygenase (Cox) 2 mRNA expression was analysed and normalised as described in a. * $P<0.05$, ${ }^{\star}{ }^{*} P<$ 0.01. (c) HC-11/R1 cells were stimulated with either $5 \mathrm{ng} / \mathrm{ml}$ recombinant murine $(\mathrm{rm}) \mathrm{IL}-1 \beta$ or $30 \mathrm{nM}$ AP20187 for the indicated times. Immunoblot analysis was performed using antibodies specific for Cox-2 and $\beta$-tubulin as a loading control. Densitometry was performed to analyse Cox- 2 expression levels relative to $\beta$-tubulin. (d) HC-11/R1 cells were treated with $30 \mathrm{nM}$ AP20187 and $5 \mathrm{ng} / \mathrm{ml} \mathrm{rmlL}-1 \beta$ for one hour. Quantitative RT-PCR analysis was performed to examine levels of Cox-2 expression, which were normalised to levels of cyclophilin and GAPDH. Error bars represent standard error of the mean. ${ }^{\star *} P<0.01,{ }^{\star \star \star} P<0.001$. (e) Migration assays were performed as described in Figure 3 . Cells were treated with $30 \mathrm{nM}$ AP20187 and/or $5 \mathrm{ng} / \mathrm{ml} \mathrm{IL-1 \beta}$ in the presence of either celecoxib or dimethyl sulfoxide (DMSO) as a solvent control as indicated. Error bars represent standard error of the mean. ${ }^{*} P<0.05,{ }^{*} P<0.01$. iFGFR1 $=$ inducible fibroblast growth factor receptor 1.

signalling pathways induced by growth factors and cytokines cooperate to promote increased levels of expression of inflammatory mediators. To determine whether iFGFR1-induced expression of Cox-2 is dependent on IL-1 $\beta$, an IL-1 $\beta$ blocking antibody was added to the media at the time of AP20187 stim- ulation and Cox-2 expression was analysed by immunoblot analysis. We found that inhibition of IL-1 $\beta$ activity did not significantly affect Cox-2 expression levels (data not shown), suggesting that iFGFR1 induces Cox-2 expression in an IL-1 $\beta$ independent manner and it is likely that IL-1 $\beta$ and iFGFR1 act 
through different signalling pathways to induce Cox-2 expression.

Because Cox-2 has been implicated in promoting breast cancer cell motility [29], we hypothesised that induction of Cox-2 was required for the synergistic effect of iFGFR1 and IL-1 $\beta$ on migration. To examine this hypothesis, HC-11/R1 cells were treated with the Cox-2 selective inhibitor, celecoxib. As shown in Figure $4 \mathrm{e}$, addition of $25 \mu \mathrm{M}$ celecoxib to the media resulted in a significant inhibition of migration induced by iFGFR1 activation. Furthermore, celecoxib also inhibited the migration induced by both iFGFR 1 and IL-1 $\beta$ (Figure 4e), suggesting that Cox-2 is a critical mediator of migration induced by iFGFR1 activation and by iFGFR1/IL-1 $\beta$ co-stimulation.

\section{iFGFR1 activation in mammary epithelial cells induces expression of Cox-2 in vivo}

To explore the mechanisms by which $\mathrm{IL}-1 \beta$ promotes the iFGFR1-induced mammary phenotype in vivo, we examined expression levels of Cox-2 following iFGFR1 activation using immunohistochemistry. As shown in Figure 5, increased expression of Cox-2 was observed in the mammary gland within 48 hours of iFGFR1 treatment (Figures 5a,c). Analysis of mammary glands following four weeks of treatment demonstrated sustained increased levels of Cox-2 associated with hyperplastic lesions (Figures $5 \mathrm{a}, \mathrm{c}$ ). To correlate the expression of Cox- 2 with IL-1 $\beta$ activity, we examined Cox- 2 expression in mammary gland sections from the mice treated with the IL-1 $\beta$ neutralising antibody. In comparison with mammary glands from mice treated with the IgG isotype control antibody, inhibition of IL-1 $\beta$ activity resulted in decreased Cox-2 expression in epithelial structures following 48 hours of treatment (Figures 5b, c). Interestingly, Cox-2 expression was not completely abolished and remained detectable in some cells (Figure 5c, arrow). Furthermore, analysis of Cox-2 mRNA expression analysed in the mammary glands by quantitative RT-PCR analysis demonstrated a decrease in Cox-2 gene expression in mammary glands from the mice treated with the IL-1 $\beta$ blocking antibody (Figure $5 d$ ). Consistent with the immunohistochemistry studies, Cox-2 gene expression was only partially reduced (Figure $5 \mathrm{~d}$ ). These results suggest that activation of iFGFR1 in mammary epithelial cells in vivo results in induction of Cox-2, which is mediated in part by IL-1 $\beta$ activity. However, inhibition of IL-1 $\beta$ activity did not completely abolish Cox-2 expression, suggesting that iFGFR1 may induce Cox-2 expression via alternate pathways as suggested by the in vitro studies.

\section{Cox-2 promotes the formation of iFGFR1-induced mammary lesions}

Although studies have demonstrated that Cox-2 promotes late-stage mammary tumourigenesis [30], the role of Cox-2 in the initial formation of early proliferative mammary lesions is unknown. Therefore, to examine the role of Cox-2 in this model, mice were provided with standard mouse chow supplemented with celecoxib for one-week prior to treatment with AP20187 to activate iFGFR1. Mice were then injected i.p. with AP20187 for 48 hours before mammary glands were removed for further analysis. Tissue samples were then stained with $\mathrm{H} \& \mathrm{E}$ for quantification of budding epithelial structures. As expected, mammary glands from mice treated with AP20187 in the absence of celecoxib exhibited increased extensive budding epithelial structures in comparison to mammary glands from non-transgenic mice treated with AP20187 (Figures 6a to $6 \mathrm{~d}$ ). Although celecoxib treatment did not completely eradicate the hyperplastic budding structures, there was a significant decrease in the percentage of extensive budding structures in mammary glands from mice given celecoxibenhanced chow following AP20187 treatment (Figure 6d). Furthermore, the number of epithelial structures with no discernible budding was increased on treatment with celecoxib (Figure 6d), suggesting a delay in the formation of the iFGFR1induced lateral budding phenotype. Notably, Cox-2 inhibition did not appear to inhibit formation of the hyperplastic lesions as well as IL-1 $\beta$ inhibition, as determined by observing whole mounts following celecoxib treatment (data not shown). This suggests that either IL-1 $\beta$ blocking antibodies are more efficient than celecoxib or that IL-1 $\beta$ can act through other downstream targets in the mammary gland. Overall, these data demonstrate that IL-1 $\beta$ and Cox-2 are involved in the formation of the iFGFR-induced hyperplastic phenotype and that targeting inflammatory mediators during early stages of mammary tumourigenesis may result in decreased formation of proliferative lesions.

\section{Discussion}

Inflammation has been linked to the development of many types of cancer, including breast cancer [1,31]. Epidemiological studies have suggested that the use of non-steroidal antiinflammatory drugs (NSAIDs) can decrease the relative risk of developing breast cancer [3-7,32,33]. These studies have led to the recent exploration of the use of Cox-2 inhibitors to treat breast cancer patients [32,34]. However, the origins of inflammation in breast cancer are still not well understood. Unlike other cancers in which chronic inflammation is associated with extrinsic factors such as bacterial or viral infection, breast cancer has not been linked to extrinsically induced inflammatory stimuli. Therefore, understanding the mechanisms by which inflammation might be induced in the breast will lead to important insights into developing anti-inflammatory strategies that may prevent the development and recurrence of invasive breast cancer.

We previously demonstrated that activation of iFGFR1 in mammary epithelial cells in vivo induced a rapid inflammatory response characterised by induction of inflammatory genes and recruitment of macrophages [14]. We have further used this model to explore the role of inflammation in promoting the formation of iFGFR1-induced hyperplastic lesions. For the current studies, we have focused on IL-1 $\beta$, which is a potent 


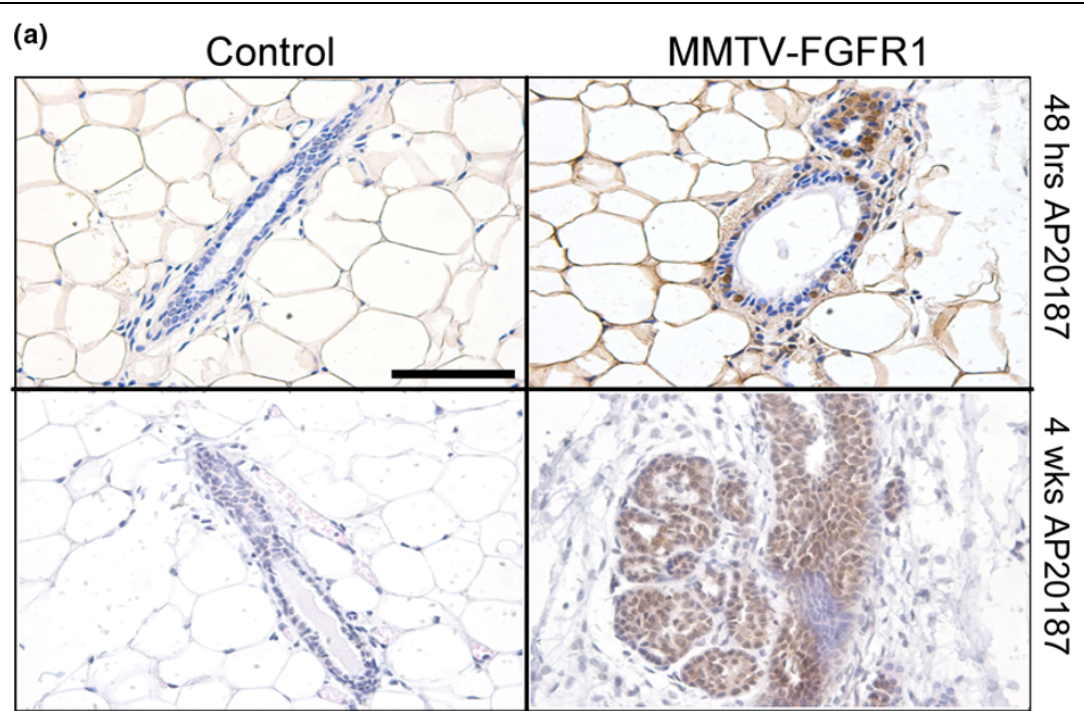

IHC: Cox-2

(b)

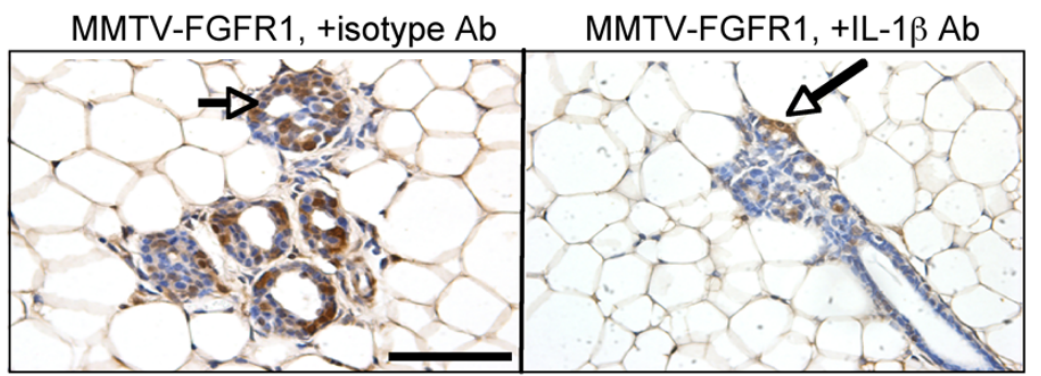

IHC: Cox-2

(c)

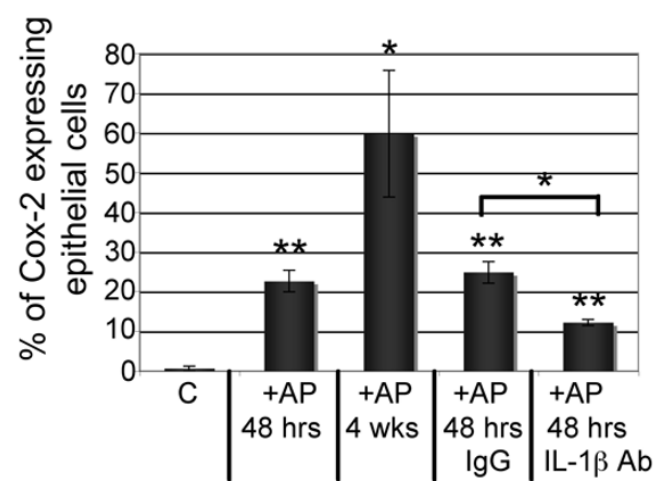

(d)

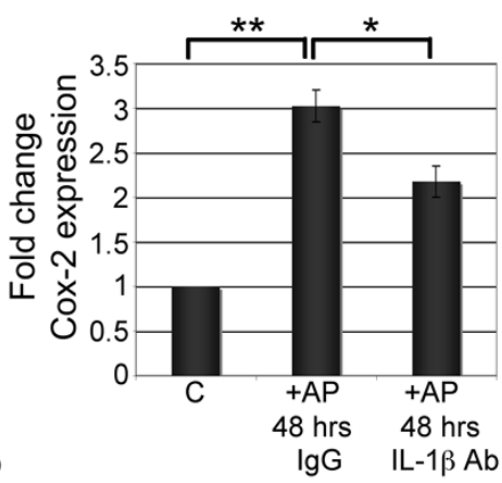

Activation of iFGFR1 induces Cox-2 expression in vivo, which is regulated in part by IL-1 $\beta$ activity. (a) Cyclooxygenase (Cox) 2 immunohistochemistry of mammary gland sections from either non-transgenic or transgenic mice treated with AP20187 for either 48 hours or 4 weeks. (b) Cox-2 immunohistochemistry of mammary gland sections from transgenic mice treated with either an isotype goat $\operatorname{lgG}$ or a neutralising IL-1 $\beta$ antibody in conjunction with AP20187 treatment. Magnification is $50 \mu \mathrm{M}$. The figure is representative of sections from three mice per treatment. (c) Percentage of epithelial cells expressing Cox-2 in panels a and b. Error bars represent standard error of the mean. ${ }^{*} P<0.05$, ${ }^{\star *} P<0.01$. (d) Quantitative RTPCR was used to analyse Cox-2 expression in mammary glands from non-transgenic and transgenic mice following treatment with AP20187 and either IgG or IL-1 $\beta$ blocking antibody. Cox-2 expression was normalised to cyclophilin expression. Error bars represent standard error of the mean. * $P<0.05,{ }^{\star \star} P<0.01$. Ab = antibody; IHC = immunohistochemistry; MMTV = mouse mammary tumour virus; $\mathrm{NF}=$ nuclear factor; iFGFR1 = inducible fibroblast growth factor receptor 1 . 


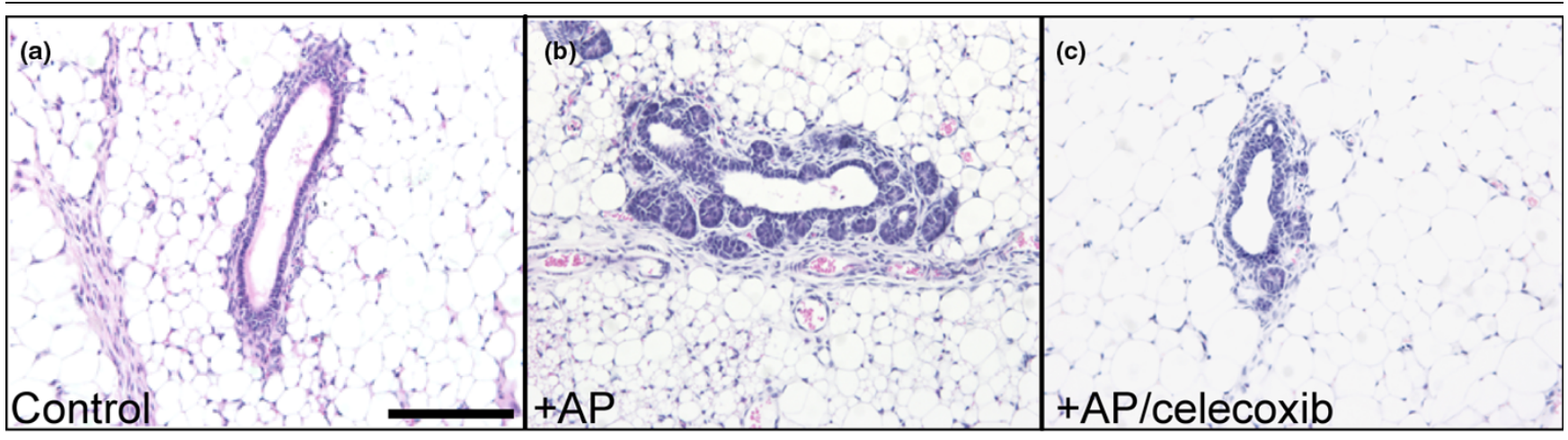

(d)

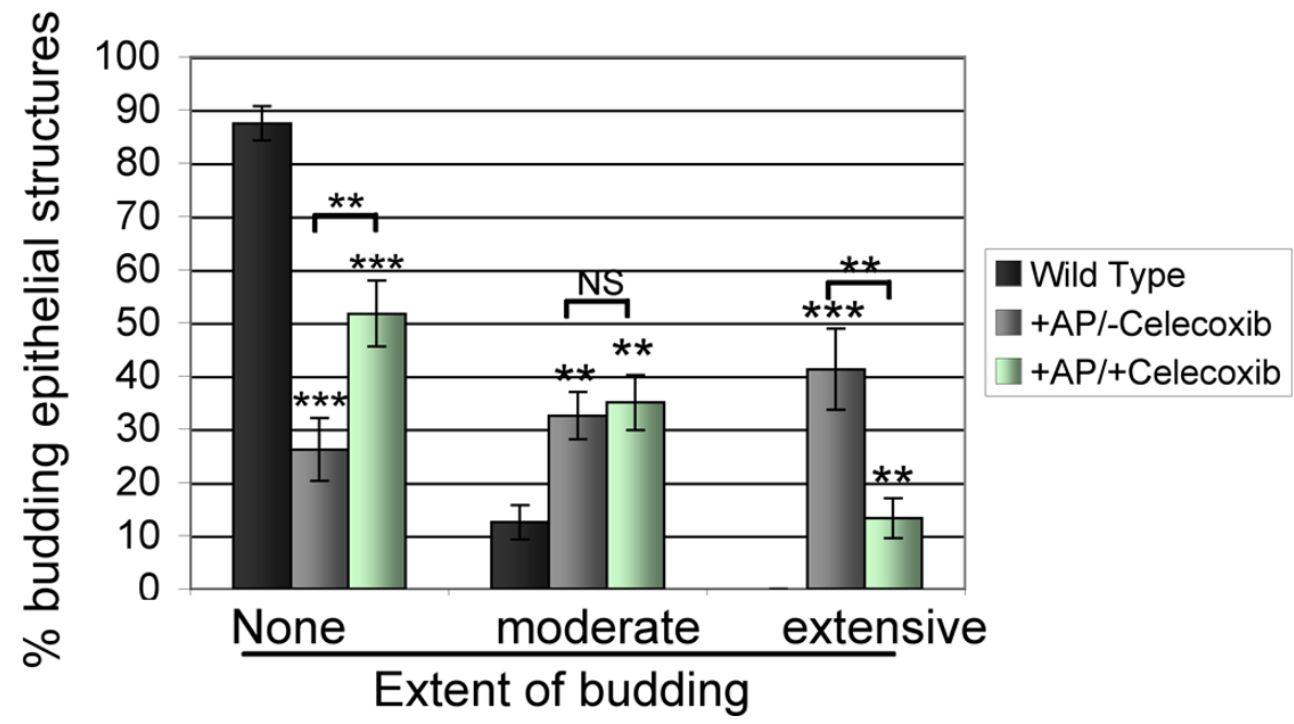

Effects of celecoxib on iFGFR1-induced mammary tumourigenesis. (a to c) H\&E-stained sections from non-transgenic control mice and mouse mammary tumour virus (MMTV) inducible fibroblast growth factor receptor 1 (iFGFR1) transgenic mice following treatment of mice with AP20187 in the presence or absence of celecoxib showing example of representative budding structures observed in each group of mice. Magnification bar $=$ $50 \mu \mathrm{M}$. (d) Extent of epithelial budding was quantified in sections from the mice described in panel a. Structures were classified as either containing no discernible budding structures (none), one to three lateral buds (moderate), or four or more budding structures (extensive) Error bars represent standard error of the mean. ${ }^{\star \star} P<0.01,{ }^{\star \star \star} P<0.001$. NS $=$ not significant.

proinflammatory cytokine that has been linked to breast cancer invasiveness and recurrence $[8,35]$. Studies of IL-1 $\beta$ in breast cancer have demonstrated that IL-1 $\beta$ expression is increased in $90 \%$ of oestrogen receptor-negative invasive breast carcinomas, and that it is localised to both tumour cells and stromal cells $[9,36]$. In vitro studies of breast cancer cells have demonstrated the ability of $\mathrm{IL}-1 \beta$ to promote proliferation and migration $[27,28]$. However, the mechanisms by which IL-1 $\beta$ acts on tumour cells and/or cells within the stroma to promote breast cancer in vivo are not well understood.

Because our results clearly demonstrate increased IL-1 $\beta$ expression in the mammary gland following iFGFR1 activation, we were interested in identifying the cell types responsible for IL-1 $\beta$ production following iFGFR1 activation. Although activation of oncogenes has been shown to induce expression of IL-
$1 \beta$ in tumour cells, we were unable to detect secreted IL-1 $\beta$ in the media of $\mathrm{HC}-11 / \mathrm{R} 1$ cells following iFGFR1 activation (data not shown). Furthermore, treatment of HC-11/R1 cells with an IL-1 $\beta$ blocking antibody at the time of AP20187 stimulation did not affect expression of Cox-2, suggesting that iFGFR1-induced expression of Cox-2 through an IL-1 $\beta$ independent pathway. However, co-culture of $\mathrm{HC}-11 / \mathrm{R} 1$ cells with either RAW 264.7 cells or bone marrow derived macrophages with HC-11/R1 cells resulted in a significant increase in IL-1 $\beta$ mRNA and protein secretion. Based on these studies, we propose that the majority of the IL-1 $\beta$ being produced in vivo is coming primarily from the macrophages, which are known to express high levels of IL-1 $\beta$ during inflammatory reactions. However, it is possible that IL-1 $\beta$ is also secreted by other cell types in the mammary gland, such as fibroblasts. Further stud- 
ies are required to delineate the mechanisms by which IL-1 $\beta$ expression is induced in this model.

It is clear that iFGFR1 activation promotes an increase in IL-1 $\beta$ within the microenvironment, which can then act on the epithelial cells to promote tumourigenesis. Therefore, further studies were performed to examine the specific effects of exogenous IL- $1 \beta$ on epithelial cells to mimic the increased levels of IL- $1 \beta$ within the microenvironment. Recent studies have demonstrated that inflammatory cytokines have profound effects on mammary epithelial cell function [37]. For example, treatment of breast cancer cells with IL-1 $\beta$ has been reported to activate the NFKB pathway and induce both cell migration and proliferation $[27,28,35]$. However, the effects of IL-1 $\beta$ on normal mammary epithelial cells have not been described. Therefore, we initially evaluated the effects of IL-1 $\beta$ on NFKB activation, proliferation and migration. IL-1 $\beta$ alone activated NFKB, suggesting that the IL-1R signalling pathway is intact in mammary epithelial cells. However, treatment of cells with IL-1 $\beta$ did not promote either migration or proliferation of the HC-11/R1 cells. Interestingly, we found that activation of iFGFR1 in the presence of exogenous IL-1 $\beta$ resulted in increased migration compared with iFGFR1 activation alone. In contrast to the lack of effect of IL-1 $\beta$ on iFGFR1-induced proliferation of the HC$11 / \mathrm{R} 1$ cells, the IL-1 $\beta$ neutralising studies suggested that IL$1 \beta$ promotes mammary epithelial cell proliferation in vivo. Therefore, it is important to consider that inflammatory mediators may have different effects on epithelial cells depending on the context of the microenvironment. In addition, it is possible that IL-1 $\beta$ affects mammary epithelial cell proliferation indirectly by acting on other cell types in the mammary gland. Further studies in which IL-1 $\beta$ signalling is impaired in specific cell types in the mammary gland would be required to elucidate these interactions.

Because Cox- 2 is a downstream target of IL- $1 \beta$, further studies focused on the ability of IL-1 $\beta$ to promote expression of Cox-2 in mammary epithelial cells. Cox-2 is expressed in human breast tumours and has been found in both early-stage atypical hyperplasias and invasive cancers [38]. However, recent studies have suggested that in contrast to previous studies, Cox-2 expression is decreased in invasive breast cancers $[34,39,40]$. Therefore, although the use of Cox-2 inhibitors in late-stage breast cancer may be limited, epidemiological studies suggest that Cox-2 inhibition may be relevant for breast cancer prevention. Interestingly, our results suggest that induction of Cox-2 expression alone is insufficient to drive tumourigenic alterations of normal epithelial cells such as migration and proliferation, because treatment of cells with IL-1 $\beta$ alone resulted in increased Cox-2 but did not promote these phenotypes. However, in combination with a single oncogenic stimulus, iFGFR1 activation, Cox-2 was able to participate in the acquisition of cell motility. These data suggest that the functions of Cox-2 in breast cancer are likely to be dependent on the stage of cancer and the context of the microenvironment rather than the levels of protein expression.

Cox-2-selective inhibitors have previously been shown to inhibit mammary tumour formation in mouse mammary tumour models [30]. However, due to the stochastic nature of these tumour models, it is difficult to determine the effects of Cox-2 inhibition during the initiating events in tumourigenesis. Because there is substantial interest in the ability of antiinflammatory drugs to reduce the risk of developing breast cancer, inducible models of mammary tumourigenesis provide a unique opportunity to study the contributions of inflammation to breast tumourigenesis. Our results from the Cox- 2 inhibition in vivo studies demonstrate that inhibition of Cox-2 prior to activating the initial oncogenic stimulus may be sufficient to delay the formation of early-stage lesions in the breast. Interestingly, gross comparison of the mammary glands using whole mounts suggested that Cox-2 inhibition did not appear to be as effective as IL-1 $\beta$ inhibition. Therefore, comparisons between different methods of inhibiting IL- $1 \beta$ and Cox- 2 in this model may provide insights into which of these inflammatory mediators might represent a more effective anti-inflammatory target. Finally, further studies of this model will provide important insights into the role of inflammation in promoting breast tumour formation, which may be particularly relevant to subsets of patients that have high levels of inflammatory mediators associated with pre-invasive lesions in the breast.

\section{Conclusions}

Studies of growth factor signalling pathways in breast cancer have produced a wealth of information regarding the effects of these pathways on tumour formation and progression. However, it is becoming more apparent that tumours are the result of a complex interplay bet ween intracellular signalling pathways and extracellular stimuli. Although several growth factor receptors, such as epidermal growth factor receptor, ErbB2 and FGFR1, have been studied and implicated in breast cancer, we are only beginning to understand how these growth factor pathways interact with other autocrine or paracrine factors to promote tumourigenesis. Although inflammatory cytokines have been implicated in breast cancer, it is clear that these cytokines alone are not sufficient to cause tumour formation. In fact, it is well accepted that cancer does not develop due to a single genetic alteration, but instead requires the contribution of multiple factors, both within the cell and in the microenvironment. Understanding how these various factors cooperate within epithelial and tumour cells to promote breast cancer initiation and formation will lead to the development of more effective combinatorial therapies designed to target multiple pathways within both the tumour cells and the supporting stromal cells.

\section{Competing interests}

The authors declare that they have no competing interests. 


\section{Authors' contributions}

JRR performed cell culture studies and the in vivo celecoxib studies, analysed the data and prepared results and contributed to drafting of the manuscript. RPL participated in the cell culture studies and performed quantitative RT-PCR analysis. $\mathrm{MKH}$ maintained the animal colony including breeding and genotyping, and performed cell culture studies. KLS conceived of the study, directed the research, performed the IL-1 $\beta$ blocking studies and drafted the manuscript.

\section{Additional files}

The following Additional files are available online:

\section{Additional file 1}

A JPG file containing images of whole mount analysis of mammary glands following inducible fibroblast growth factor receptor 1 activation and IL-1 $\beta$ inhibition. Mammary glands from non-transgenic, non-treated mice (control) and transgenic mice treated with AP20187, IgG isotype control or IL-1 $\beta$ blocking antibody were analysed by whole mount analysis.

See http://www.biomedcentral.com/content/ supplementary/bcr2246-S1.jpeg

\section{Acknowledgements}

We would like to thank Dr Jeff Rosen for providing reagents used in these studies, Dr Jim McCarthy for helpful discussions and use of densitometer, and Colleen Forster for help with tissue sectioning. In addition, we would like to acknowledge the use of the confocal microscope made available through an NCRR Shared Instrumentation Grant (\#1 S10 RR16851). This work was supported in part by funds from the Masonic Cancer Center, University of Minnesota Translational Breast Cancer Award, the Minnesota Medical Foundation (\#3800-9227-07), an American Cancer Society Institutional Research Grant (IRG \#21) and a Susan G Komen for the Cure Career Catalyst Award (KG081326).

\section{References}

1. Coussens LM, Werb Z: Inflammation and cancer. Nature 2002, 420:860-867.

2. Allavena P, Sica A, Garlanda C, Mantovani A: The Yin-Yang of tumor-associated macrophages in neoplastic progression and immune surveillance. Immunol Rev 2008, 222:155-161.

3. Gallicchio L, Visvanathan K, Burke A, Hoffman SC, Helzlsouer KJ: Nonsteroidal anti-inflammatory drugs and the risk of developing breast cancer in a population-based prospective cohort study in Washington County, MD. Int J Cancer 2007, 121:211-215.

4. Gonzalez-Perez A, Garcia Rodriguez LA, Lopez-Ridaura R: Effects of non-steroidal anti-inflammatory drugs on cancer sites other than the colon and rectum: a meta-analysis. BMC Cancer 2003, 3:28.

5. Harris RE, Chlebowski RT, Jackson RD, Frid DJ, Ascenseo JL, Anderson G, Loar A, Rodabough RJ, White E, McTiernan A: Breast cancer and nonsteroidal anti-inflammatory drugs: prospective results from the Women's Health Initiative. Cancer Res 2003, 63:6096-6101.

6. Khuder SA, Mutgi AB: Breast cancer and NSAID use: a metaanalysis. Br J Cancer 2001, 84:1188-1192.
7. Kwan ML, Habel LA, Slattery ML, Caan B: NSAIDs and breast cancer recurrence in a prospective cohort study. Cancer Causes Control 2007, 18:613-620.

8. Nicolini A, Carpi A, Rossi G: Cytokines in breast cancer. Cytokine Growth Factor Rev 2006, 17:325-337.

9. Pantschenko AG, Pushkar I, Anderson KH, Wang Y, Miller LJ, Kurtzman SH, Barrows G, Kreutzer DL: The interleukin-1 family of cytokines and receptors in human breast cancer: implications for tumor progression. Int J Oncol 2003, 23:269-284.

10. Howe LR: Inflammation and breast cancer. Cyclooxygenase/ prostaglandin signaling and breast cancer. Breast Cancer Res 2007, 9:210.

11. Singh B, Cook KR, Vincent L, Hall CS, Berry JA, Multani AS, Lucci $A$ : Cyclooxygenase-2 induces genomic instability, BCL2 expression, doxorubicin resistance, and altered cancer-initiating cell phenotype in MCF7 breast cancer cells. J Surg Res 2008, 147:240-246.

12. Chun KS, Surh YJ: Signal transduction pathways regulating cyclooxygenase-2 expression: potential molecular targets for chemoprevention. Biochem Pharmacol 2004, 68:1089-1100.

13. Subbaramaiah K, Norton L, Gerald W, Dannenberg AJ: Cyclooxygenase-2 is overexpressed in HER-2/neu-positive breast cancer: evidence for involvement of AP-1 and PEA3. J Biol Chem 2002, 277:18649-18657.

14. Schwertfeger KL, Xian W, Kaplan AM, Burnett SH, Cohen DA, Rosen JM: A critical role for the inflammatory response in a mouse model of preneoplastic progression. Cancer Res 2006, 66:5676-5685.

15. Welm BE, Freeman KW, Chen M, Contreras A, Spencer DM, Rosen JM: Inducible dimerization of FGFR1: development of a mouse model to analyze progressive transformation of the mammary gland. J Cell Biol 2002, 157:703-714.

16. Xian W, Schwertfeger KL, Vargo-Gogola T, Rosen JM: Pleiotropic effects of FGFR1 on cell proliferation, survival, and migration in a 3D mammary epithelial cell model. J Cell Biol 2005, 171:663-673.

17. Chin K, DeVries S, Fridlyand J, Spellman PT, Roydasgupta R, Kuo WL, Lapuk A, Neve RM, Qian Z, Ryder T, Chen F, Feiler H, Tokuyasu T, Kingsley C, Dairkee S, Meng Z, Chew K, Pinkel D, Jain A, Ljung BM, Esserman L, Albertson DG, Waldman FM, Gray JW: Genomic and transcriptional aberrations linked to breast cancer pathophysiologies. Cancer Cell 2006, 10:529-541.

18. Shchors K, Shchors E, Rostker F, Lawlor ER, Brown-Swigart L, Evan Gl: The Myc-dependent angiogenic switch in tumors is mediated by interleukin 1beta. Genes Dev 2006, 20:2527-2538.

19. Grimm SL, Rosen JM: The role of C/EBPbeta in mammary gland development and breast cancer. J Mammary Gland Biol Neoplasia 2003, 8:191-204.

20. Yuen T, Zhang W, Ebersole BJ, Sealfon SC: Monitoring G-protein-coupled receptor signaling with DNA microarrays and real-time polymerase chain reaction. Methods Enzymol 2002, 345:556-569.

21. Livak KJ, Schmittgen TD: Analysis of relative gene expression data using real-time quantitative PCR and the 2(-Delta Delta C(T)) Method. Methods 2001, 25:402-408.

22. Elsheikh SE, Green AR, Lambros MB, Turner NC, Grainge MJ, Powe D, Ellis IO, Reis-Filho JS: FGFR1 amplification in breast carcinomas: a chromogenic in situ hybridisation analysis. Breast Cancer Res 2007, 9:R23.

23. Xian W, Schwertfeger KL, Rosen JM: Distinct roles of fibroblast growth factor receptor 1 and 2 in regulating cell survival and epithelial-mesenchymal transition. Mol Endocrinol 2007, 21:987-1000.

24. Ball RK, Friis RR, Schoenenberger CA, Doppler W, Groner B: Prolactin regulation of beta-casein gene expression and of a cytosolic 120 -kd protein in a cloned mouse mammary epithelial cell line. Embo J 1988, 7:2089-2095.

25. Apte RN, Voronov E: Is interleukin-1 a good or bad 'guy' in tumor immunobiology and immunotherapy? Immunol Rev 2008, 222:222-241.

26. Dinarello CA: The IL-1 family and inflammatory diseases. Clin Exp Rheumato/ 2002, 20:S1-13.

27. Streicher KL, Willmarth NE, Garcia J, Boerner JL, Dewey TG, Ethier SP: Activation of a nuclear factor kappaB/interleukin-1 positive feedback loop by amphiregulin in human breast cancer cells. Mol Cancer Res 2007, 5:847-861. 
28. Wang FM, Liu HQ, Liu SR, Tang SP, Yang L, Feng GS: SHP-2 promoting migration and metastasis of MCF-7 with loss of Ecadherin, dephosphorylation of FAK and secretion of MMP-9 induced by IL-1 beta in vivo and in vitro. Breast Cancer Res Treat 2005, 89:5-14.

29. Singh B, Berry JA, Shoher A, Ramakrishnan V, Lucci A: COX-2 overexpression increases motility and invasion of breast cancer cells. Int J Oncol 2005, 26:1393-1399.

30. Lanza-Jacoby S, Miller S, Flynn J, Gallatig K, Daskalakis C, Masferrer JL, Zweifel BS, Sembhi H, Russo IH: The cyclooxygenase-2 inhibitor, celecoxib, prevents the development of mammary tumors in Her-2/neu mice. Cancer Epidemiol Biomarkers Prev 2003, 12:1486-1491.

31. DeNardo DG, Coussens LM: Inflammation and breast cancer. Balancing immune response: crosstalk between adaptive and innate immune cells during breast cancer progression. Breast Cancer Res 2007, 9:212.

32. Mazhar D, Ang R, Waxman J: COX inhibitors and breast cancer. Br J Cancer 2006, 94:346-350.

33. Terry MB, Gammon MD, Zhang FF, Tawfik H, Teitelbaum SL, Britton JA, Subbaramaiah K, Dannenberg AJ, Neugut Al: Association of frequency and duration of aspirin use and hormone receptor status with breast cancer risk. JAMA 2004, 291:2433-2440.

34. Dirix LY, Ignacio J, Nag S, Bapsy P, Gomez H, Raghunadharao D, Paridaens $R$, Jones $S$, Falcon $S$, Carpentieri M, Abbattista A, Lobelle JP: Treatment of advanced hormone-sensitive breast cancer in postmenopausal women with exemestane alone or in combination with celecoxib. J Clin Oncol 2008, 26:1253-1259.

35. Lewis AM, Varghese $\mathrm{S}, \mathrm{Xu} \mathrm{H}$, Alexander HR: Interleukin-1 and cancer progression: the emerging role of interleukin-1 receptor antagonist as a novel therapeutic agent in cancer treatment. J Transl Med 2006, 4:48.

36. Kurtzman $\mathrm{SH}$, Anderson $\mathrm{KH}$, Wang $\mathrm{Y}$, Miller LJ, Renna M, Stankus $M$, Lindquist RR, Barrows G, Kreutzer DL: Cytokines in human breast cancer: IL-1alpha and IL-1beta expression. Oncol Rep 1999, 6:65-70.

37. Khaled WT, Read EK, Nicholson SE, Baxter FO, Brennan AJ, Came PJ, Sprigg N, McKenzie AN, Watson CJ: The IL-4/IL-13/ Stat6 signalling pathway promotes luminal mammary epithelial cell development. Development 2007, 134:2739-2750.

38. Half E, Tang XM, Gwyn K, Sahin A, Wathen K, Sinicrope FA: Cyclooxygenase-2 expression in human breast cancers and adjacent ductal carcinoma in situ. Cancer Res 2002, 62:1676-1681.

39. Boneberg EM, Legler DF, Senn HJ, Furstenberger G: Reduced expression of cyclooxygenase-2 in primary breast cancer. $J$ Natl Cancer Inst 2008, 100:1042-1043.

40. Zhao X, Goswami M, Pokhriyal N, Ma H, Du H, Yao J, Victor TA, Polyak K, Sturgis CD, Band $\mathrm{H}$, Band V: Cyclooxygenase-2 expression during immortalization and breast cancer progression. Cancer Res 2008, 68:467-475. 